\title{
APPLICATIONS OF THE DIMENSIONAL-MEASURING LASER INTERFEROMETER IN THE OAK RIDGE Y-12 PLANT GAGE LABORATORY
}

B. M. Burrus

prepared for the U.S. ENERGY RESEARCH AND DEVELOPMENT ADMINISTRATION under U.S. GOVERNMENT Contract W-7405 eng 26 OAK RIDGE. TENNESSEE

\section{MASIER}




\section{DISCLAIMER}

This report was prepared as an account of work sponsored by an agency of the United States Government. Neither the United States Government nor any agency Thereof, nor any of their employees, makes any warranty, express or implied, or assumes any legal liability or responsibility for the accuracy, completeness, or usefulness of any information, apparatus, product, or process disclosed, or represents that its use would not infringe privately owned rights. Reference herein to any specific commercial product, process, or service by trade name, trademark, manufacturer, or otherwise does not necessarily constitute or imply its endorsement, recommendation, or favoring by the United States Government or any agency thereof. The views and opinions of authors expressed herein do not necessarily state or reflect those of the United States Government or any agency thereof. 


\section{DISCLAIMER}

Portions of this document may be illegible in electronic image products. Images are produced from the best available original document. 
Reference to a company or product name does not imply approval or recommendation of the product by Union Carbide Corporation or the U.S. Energy Research and Development Administration to the exclusion of others that may meet specifications.

Printed in the United States of America. Available from National Technical Information Service

U.S. Department of Commerce

5285 Port Royal Road, Springfield, Virginia 22161

Price: Printed Copy $\$ 4.00$; Microfiche $\$ 3.00$

This report was prepared as an account of work sponsored by the United States Government. Neither the United States nor the Energy Research and Development Administration, nor any of their employees, nor any of their contractors, subcontractors, or their employees, makes any warranty, express or implied, or assumes any legal liability or responsibility for the accuracy, completeness or usefulness of any information, apparatus, product or process disclosed, or represents that its use would not infringe privately owned rights. 


\title{
APPLICATIONS OF THE DIMENSIONAL-MEASURING LASER INTERFEROMETER IN THE OAK RIDGE Y-12 PLANT GAGE LABORATORY
}

\author{
B. M. Burrus
}

Standards and Surveys Department

Y-12 Technical Division

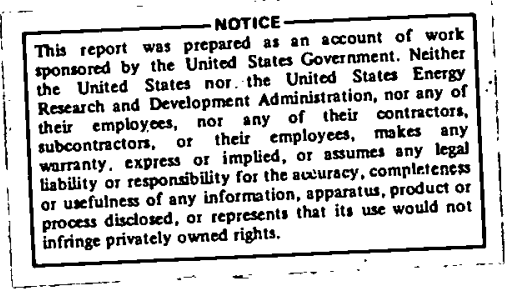

Oak Ridge Y-12 Plant

P. O. Box Y, Oak Ridge, Tennessee 37830

Prepared for the US Energy Research

and Development Adminlstration

Under US Government Contract W-7405-eng-26 


\begin{abstract}
This report gives a layman's explanation of the operating principles of the dimensionalmeasuring laser interferometer, and a description, including photographs and illustrations, of the use of a portable laser interferometer in calibrating dimensional standards and measuring equipment in the Oak Ridge Y-12 Plant Gage Laboratory.
\end{abstract}




\section{CONTENTS}

SUMMARY $\ldots \ldots \ldots \ldots \ldots \ldots \ldots \ldots \ldots \ldots \ldots \ldots \ldots \ldots \ldots \ldots \ldots$

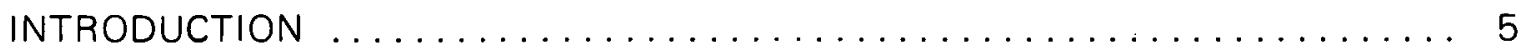

APPLICATIONS OF THE DIMENSIONAL-MEASURING LASER INTER-

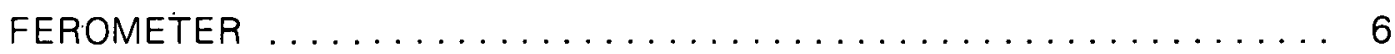

Gage Laboratory Operations $\ldots \ldots \ldots \ldots \ldots \ldots \ldots \ldots \ldots \ldots \ldots \ldots \ldots$

Principles of Dimensional-Measuring Interferometry $\ldots \ldots \ldots \ldots \ldots \ldots \ldots \ldots$

Laser Tube ............................... 7

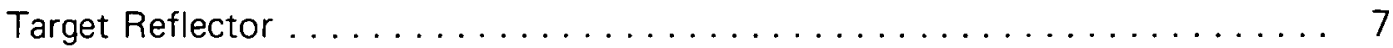

Remote Interferometer $\ldots \ldots \ldots \ldots \ldots \ldots \ldots \ldots \ldots \ldots \ldots \ldots$

Fixed Interferometer and Photoelectric Detectors . . . . . . . . . . . . 10

Display Console . . . . . . . . . . . . . . . . . . . . . . 10

Applications of the Dimensional-Measuring Laser Interferometer in the

Y-12 Gage Laboratory . . . . . . . . . . . . . . . . . 10

Calibration of Three-Axis Measuring Machines . . . . . . . . . . . . . 11

Calibration of Step Gages . . . . . . . . . . . . . . . . . . . . . . 14

Calibration of Linearity Checkers . . . . . . . . . . . . . . . . . . 16

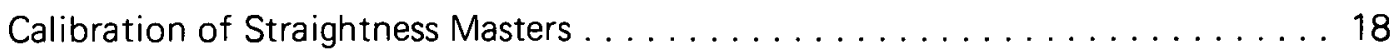

Calibration of Large Vernier Calipers . . . . . . . . . . . . . . . . . 20

Certification, Maintenance, and Transport of the Portable Laser System . . . . . . . . 20

Certification of Measurement Accuracy . . . . . . . . . . . . . . . . . . 22

Calibration of the Automatic Compensator . . . . . . . . . . . . . . 22

Annual Instrument Certification and Maintenance . . . . . . . . . . . . . 24

Handling and Transport . . . . . . . . . . . . . . . . . . 27

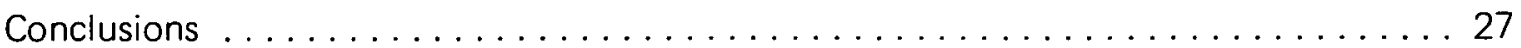




\section{SUMMARY}

The dimensional-measuring, portable, laser interferometer has become a standard measuring tool in the $Y-12$ Plant Gage Laboratory. It has been found to be a versatile and dependable tool. The instrument has been successful in improving accuracy and reducing calibration time in virtually every laser application. A workable set of procedures for the use, calibration, and handling of the portable laser interferometer measuring system is presented in this report. 


\section{INTRODUCTION}

Interest in laser interferometry as a dimensional measuring tool has increased considerably in recent years. Numerous inspection and calibration laboratories use laser interferometry routinely. Many non-users are presently in the process of investigating its application with reference to their operations; others are seriously considering its use. Since personnel at the Oak Ridge Y-12 Plant(a) have been using laser interferometry for several years as a dimensional measuring system in the calibration of gages, standards, and measuring machines, it is felt that a report on the experience gained during this time would be of value to many of those in the measurement field using, or contemplating the use of, laser measuring systems. The primary objective in this report is to describe and illustrate some practical applications of the dimensional-measuring laser interferometer in the laboratory. In this endeavor, a discussion of the basic operating principles of laser interferometry has been included. Illustrations of actual on-the-job applications are presented; also, some direct English-to-SI (b) conversions that have recently been made on permanent measuring systems have been evaluated.

Even though the Hewlett-Packard Model $5525 \mathrm{~A} / \mathrm{B}$ portable laser measuring system is the instrument in use in the $Y-12$ Plant Gage Laboratory, this particular unit has been considerably improved by recent modifications and ensuing model changes. It is intended in this report to describe the operating principles and measurement applications of laser systems in general and not to restrict the discussions to one particular system or model.

(a) Operated by the Union Carbide Corporation's Nuclear Division for the US Energy Research and Development Administration.

(b) SI-Système International d'Unités-a modernization of the Metric System for international use. 


\section{APPLICATIONS OF THE DIMENSIONAL-MEASURING LASER INTERFEROMETER}

\section{GAGE LABORATORY OPERATIONS}

The Y-12 Plant Gage Laboratory has two missions: (1) to maintain dimensional measurement standards directly traceable to the National Bureau of Standards (NBS) or another authoritative source, and (2) to provide dimensional calibration services as required by the $\mathrm{Y}-12$ Plant, and by $\mathrm{Y}-12$ customers. Fulfilling the second mission requires that approximately 6000 items of inspection equipment, including approximately 100 measuring machines, be calibrated at regular intervals. These measuring machines range from Iwelve-Inch Supermicrometers to multiaxis machines with more than six feet of travel. An average of 25 items, ranging from thread gages to angle blocks and from three-dimensional functional gages to multiaxis measuring machines, are calihrated each day. The time required to calibrate a single gage may range from 20 minutes to 20 mandays.

The Laboratory staff, consists of six technical and supervisory personnel, two clerical personnel, and 20-30 inspectors (depending on the plant workload level). One supervisor and approximately one half of the inspectors spend their full time calibrating measuring equipment in the plant's many inspection areas; the remainder of the staff perform their work in the Laboratory on standards and items that are routinely shipped to the Laboratory for calibration. The clerical staff maintains a computerized rccall program. (c) Procedures prepared by the technical staff are used in the performance of all calibrations.

The Laboratory includes approximately 12,000 square feet of floor space, of which 1200 square feet is devoted to the maintenance and care of measurement standards. The entire Laboratury area is environmentally controlled. Total capital investment in the Gage Laboratory is approximately $\$ 1,000,000$; the annual operating rnst is anproximately $\$ 900,000$. It can be seen that the cost of a portable laser-interferometer measuring system $(\$ 30,000-\$ 40,000)$ is relatively small compared to the annual cost for Gage Laboratory operations. Purchase of a portable laser interferometer was justified on the basis of anticipated improvements in measuring accuracy and a reduction in the time required for calibrating large measuring machines. However, the laser system has also proved to be a very practical measuring instrument in many other measurement applications in the Lahoratory.

\section{PRINCIPLES OF DIMENSIONAL-MEASURING LASER INTERFEROMETRY}

For those who are not already familiar with the dimensional-measuring laser interferometer, a simplified explanation of the principles involved might be worthwhile. The system consists

(c) Davis, R. L.; A Gage Calibration and Control System, Y-DJ-10,783; Union Carbide Corporation-Nuclear Division, Oak Ridge Y-12 Plant, Oak Ridge, Tennessee; November $14,1972$. 
of five major components: (1) a laser tube, (2) a target reflector, (3) a remote interferometer, (4) a fixed interferometer and photoelectric detectors, and (5) the display console (computer electronics, manual controls, and digital readout). Each will be described in some detail.

\section{Laser Tube}

The laser tube (Figure 1) contains a low-pressure gas (usually a mixture of helium and neon). An electric current passing through the tube excites the helium and neon atoms, causing rapid collisions. The energized atoms, on collision, release their energy in the form of light. Some of the trapped light is reflected back and forth between reflecting mirrors located at each end of the laser tube. The mirror at the end of the tube where the laser beam is emitted has slightly less reflectivity than the other mirror; hence, 2 - $5 \%$ of the reflected light escapes as a bright, coherent beam called the laser beam (Figure 1). Laser beams are unlike ordinary light in that ordinary light is not coherent, and it diverges quickly in all directions at various frequencies. Laser beams, on the other hand, can travel great distances without noticable divergence.

\section{Target Reflector}

The laser beam emitted from the laser tube strikes the target reflector (Figure 1) that is attached to the moving part. The target reflector (a trihedral prism) reflects the laser beam back in a path precisely parallel to the entering beam, as long as the incident beam is less than 15 degrees from normal.

\section{Remote Interferometer}

The remote interferometer (Figure 1) is actually an accessory, but a very necessary one, for making precision measurements. $Y-12$ Gage Laboratory's portable laser measuring system (Hewlett-Packard,. Model $5525 \mathrm{~A} / \mathrm{B}$ ) will operate just as well without the remote interferometer, but with less accuracy. Without the remote interferometer, the returning laser beam is combined with a previously deflected portion of this beam in the fixed interferometer located inside the laser head housing with the laser tube. When the remote interferometer is used, the reference point for measurement moves from the fixed interferometer to the remote interferometer, significantly reducing a major meașurement error called the "dead-path error" (Figure 2). Any movement of the laser head relative to the remote interferometer will not affect the measurement as long as the beam alignment is maintained within the aperture range. Measurement error due to changes in environmental conditions in the zone between the laser head and the remote interferometer is also eliminated.

The laser beam, after striking the target mirror, is reflected back in a parallel path and is combined with a reference beam in the remote interferometer and returned to the fixed interfernmeter optics inside the laser head where a fringe is formed for every quarter wavelength of movement of the target reflector. (The fixed, or internal, interferometer has 


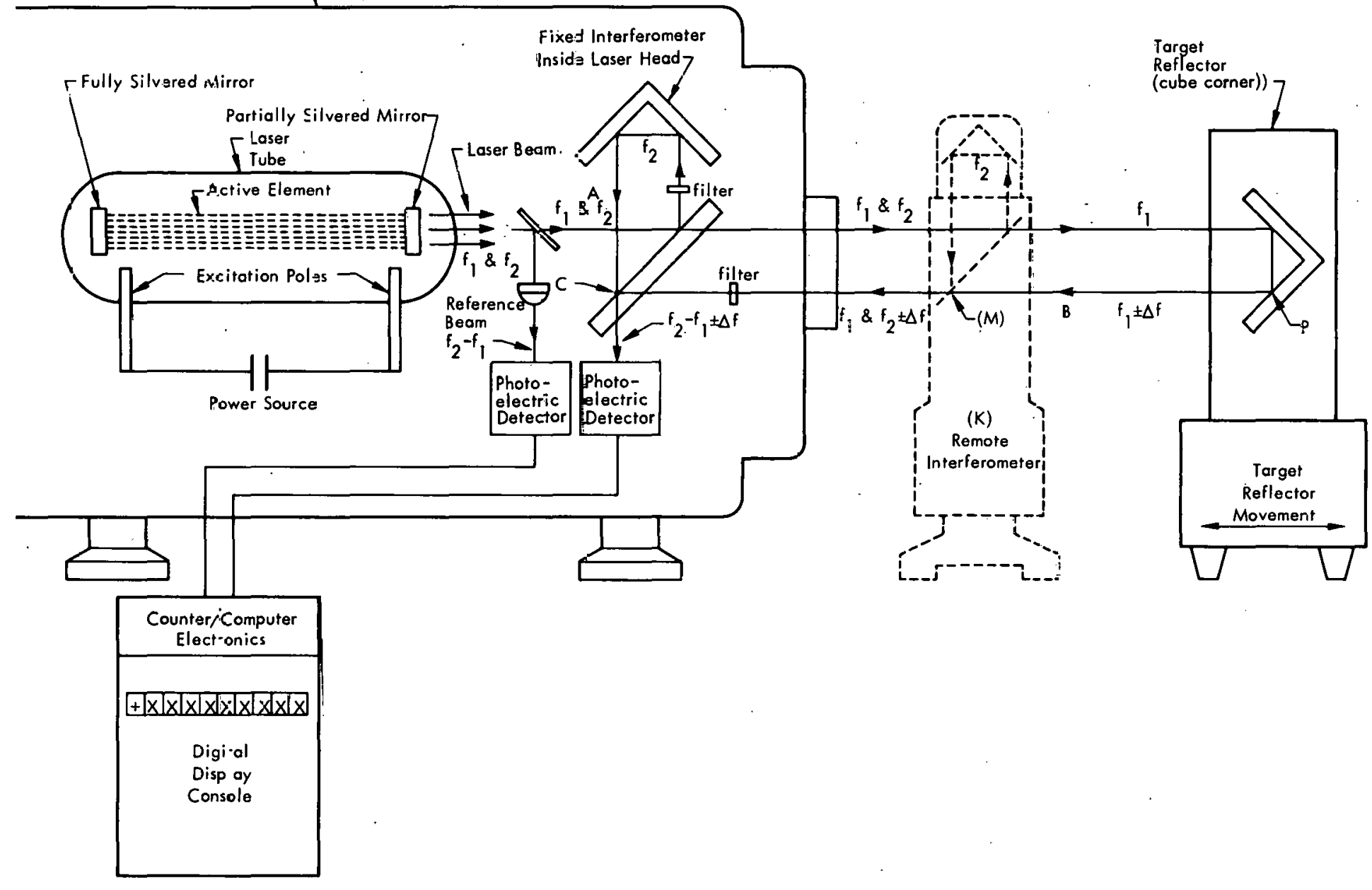

Figure 1. DIMENSIONAL-MEASURIVG LASER INTERFEROMETER WITH REMOTE INTERFERDMETER. [The Laser Interferometer SYstem (HP 5525 $A / B)$ can be Used with o- without a Remote Interferometer; when the Remote Interferometer $s$ Used, it is Placed it Posi-ion K; the Reference Point for the Measurement is then Located at Point $M$, as Opposed to Poini $C$ without the Remote Interferometer; the Change in Wavelength between Points $C$ and $M$, due to Environmental Changes, ihen has no Effect on the Measurement; also, any Movement of the Laser Head with Respect to the Remote Interferometer will not Affect the Measurement; the Remote Interferometer should be Placed as Close as Possible to the Target Reflector in Order to Remove the Maximum Amount of IDead-Path Error between Points $C$ and P]l. 


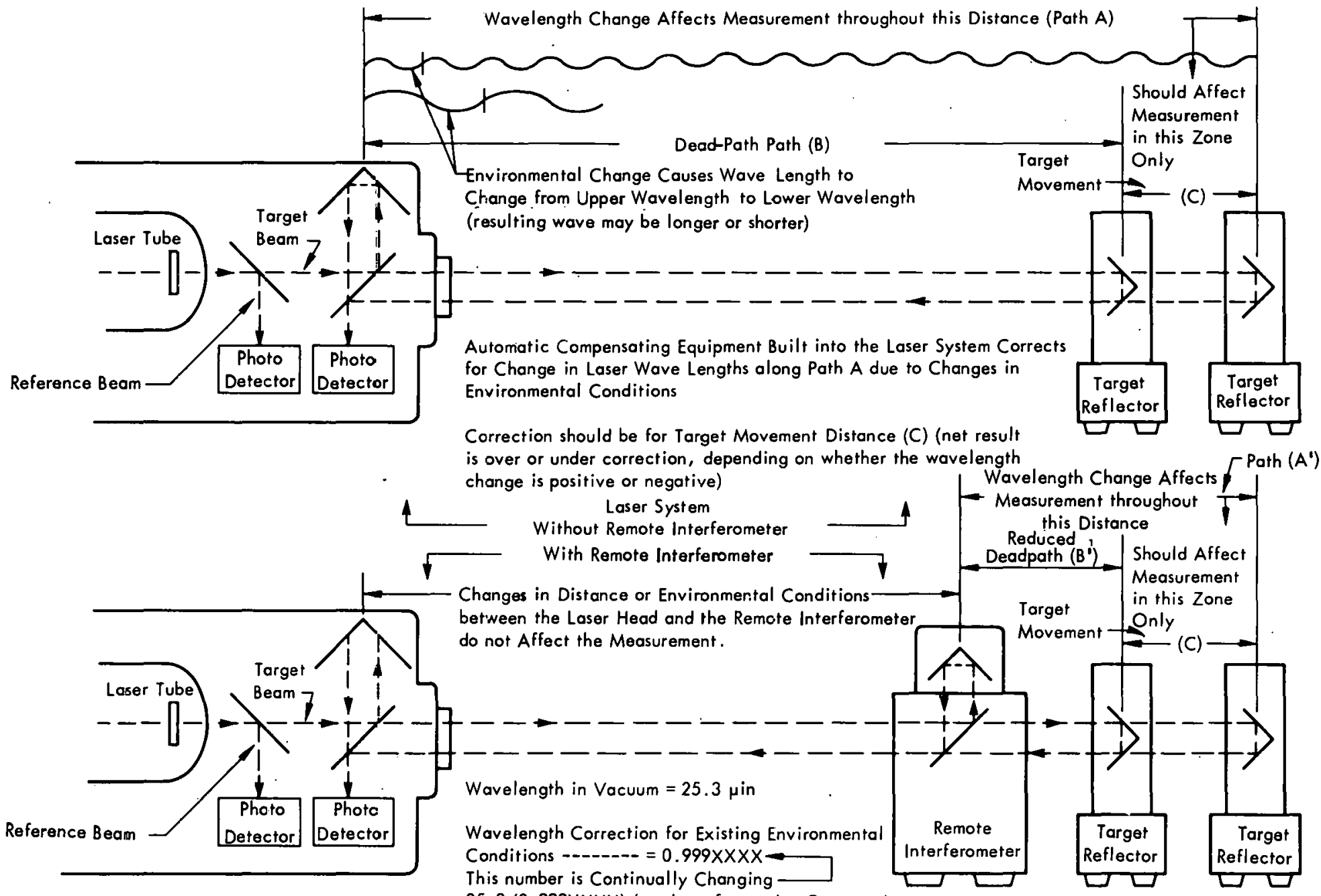

$25.3(0.999 \times X X X)$ (number of woves) = Corrected Measurement

Figure 2. PRINCIPLE OF THE LASER DEAD-PATH CORRECTION. (If there is no Environmental Change during a Measurement, there wil! be no DeadPath Error; Measurement will be Overcorrected or Undercorrected if there is a Change in Environmental Conditions during the Measurement; Amount of Error will Depend on the Amount of Dead.Path; this Error can be Reduced by Reducing the Dead Path, but can never be Completely Eliminated). 
been eliminated in some of the more recent models of laser measuring systems, and only the remote interferometer is required.)

\section{Fixed Interferometer and Photoelectric Detectors}

The method of counting wavelengths involves the interference of three frequencies (Figure 1), two slightly different frequencies emitted from the laser tube, and a delta frequency resulting from the movement of the target reflector. A detailed explanation of the principles of wave (fringe) counting would involve a discussion of the theory of relative motion of waves, Doppler shifts, and other optical-wave phenomena. Simply stated, each fringe formed in the fixed-interferometer optics represents a movement of the target refles.tor equial tn $1 / 4$ wavelength of the laser beam light. A photoelectric detector senses these fringes and relays corresponding pulses to the counter computer in the digital display console. Length of $1 / 4$ wavelength of the laser beam is known to an accuracy of approximately five parts in ten million (or $1 / 2$ part per million). One-quarter wavelength of the helium-neon laser light is equal to 1582 angstroms, or 6.23 microinches $(0.16 \mu \mathrm{m}$ ). The resolution (smallest unit of measure) of the Hewlett-Packard' 5525 A/B laser depends on whether the unit is programmed for the English or SI system of measure. The resolution is $0.01 \mu \mathrm{m}$ when using the SI system, and $1 \mu$ in when the English measuring system is being used. Since, in both cases, the instrument resolution is considerably less than the length of $1 / 4$ wavelength of laser beam light, it is evident that the $1 / 4$ wavelength must be further subdivided into smaller units before a measurement can be displayed. This subdivision is accomplished through digital-phase interpolation within the computer electronic system, a mathematical manipulation process of subdividing the distance between light fringes into much finer increments.

\section{Display Console}

The display console (Figure 1) houses the electronics which convert the pulses received from the photoelectric detectors to units of length, and digitally displays the measurement in English, SI, or $1 / 4$ wavelength units. All setup, operational, and environmental correction adjustments are located on the face of the display console. A digital recorder is alsn availahle as an accessory.

When the laser interferometer is transported to another location, the laser head, reflectors, and remote interferometer are positioned inside the display console. Some photographs are presented later in this report that illustrate the compactness and mobility of the system.

\section{APPLICATIONS OF THE DIMENSIONAL-MEASURING LASER INTERFEROMETER IN THE Y-12 GAGE LABORATORY}

Prior sections of this report were devoted to an introduction to the $\mathrm{Y}-12$ Gage Laboratory and a general description of the functions performed. Also, the basic operating principles of a dimensional-measuring laser interferometer system were discussed. This section is devoted to a discussion of actual (on-the-job) use of the portable laser interferometer as a 
dimensional measuring system. Photographs are shown, together with a description of the operations performed, involving the calibration of a variety of gages, standards, and measuring machines.

\section{Calibration of 3-Axis Measuring Machines}

As mentioned earlier (Page 6), purchase of portable laser measuring equipment was justified on the basis of an improvement in measurement accuracy and a reduction in the time required to calibrate large measuring machines. Figure 3 is a view of the laser system being used to calibrate the measuring systems of a SIP 7AM measuring machine.

In the setup shown, the measuring system on the SIP 7 AM machine table is being calibrated. The table is moved to each succeeding randomly selected position and located by using the machine measuring system. This distance is then compared to the laser readout. The laser sensing head is located on a precision and stable positioning device; the cube corner (target) reflector is located on the front of the machine bed. The remote interferometer can be seen on top of a magnetic spacer and angle plate. The angle plate is attached to the forward end of the machine housing. The accuracy of the measuring system on the machine bed transverse axis is checked at random points throughout its 54 inches of travel. Horizontal travel of the bridge is checked in a similar manner. The horizontal bridge cannot be seen in this view, however, as it extends beyond the limits of the picture. The 72 inches of vertical ram travel are calibrated by positioning a 90-degree beam bender on the machine bed and moving the cube corner (target) reflector to a position on the vertical ram. Pitch and yaw of each of these movements are also checked with the laser, using specially designed optical reflectors which can be seen in a later photo (Figure 7). Details of the pitch-yaw reflector are illustrated in Figure 4. The digital display is located on the uppermost section of the laser console. The digital display console (Figure 3 ) is located in a position for the best overall view of all equipment. Normally, the console would be facing the inspector who is operating the machine. One inspector can usually perform this calibration without assistance.

Velocity (feeds or speeds) of any of the machine linear-motion characteristics can be determined independently, or during a measurement operation. A velocity push button is located on the console panel. Velocity measurements can be made and digitally displayed without affecting the linear distance data or reference points.

Approximately 150 calibrations involving major measuring machines similar to the one shown in Figure 3 are made annually by Gage Laboratory personnel. An average of 30 manhours is required for each calibration. A portable laser measuring system is used in approximately $60 \%$ of all measuring-machine calibration work. Recent estimates indicate that calibration time is reduced approximately $30 \%$ by using the laser system to calibrate the major measuring machines. Measurement accuracies, using the laser system, show an average improvement ratio of 2 to 1 over conventional calibration methods. This ratio is somewhat less when measuring consecutive one-inch intervals up to 24 inches; the ratio is considerably higher when measuring randomly selected check points or when measuring 


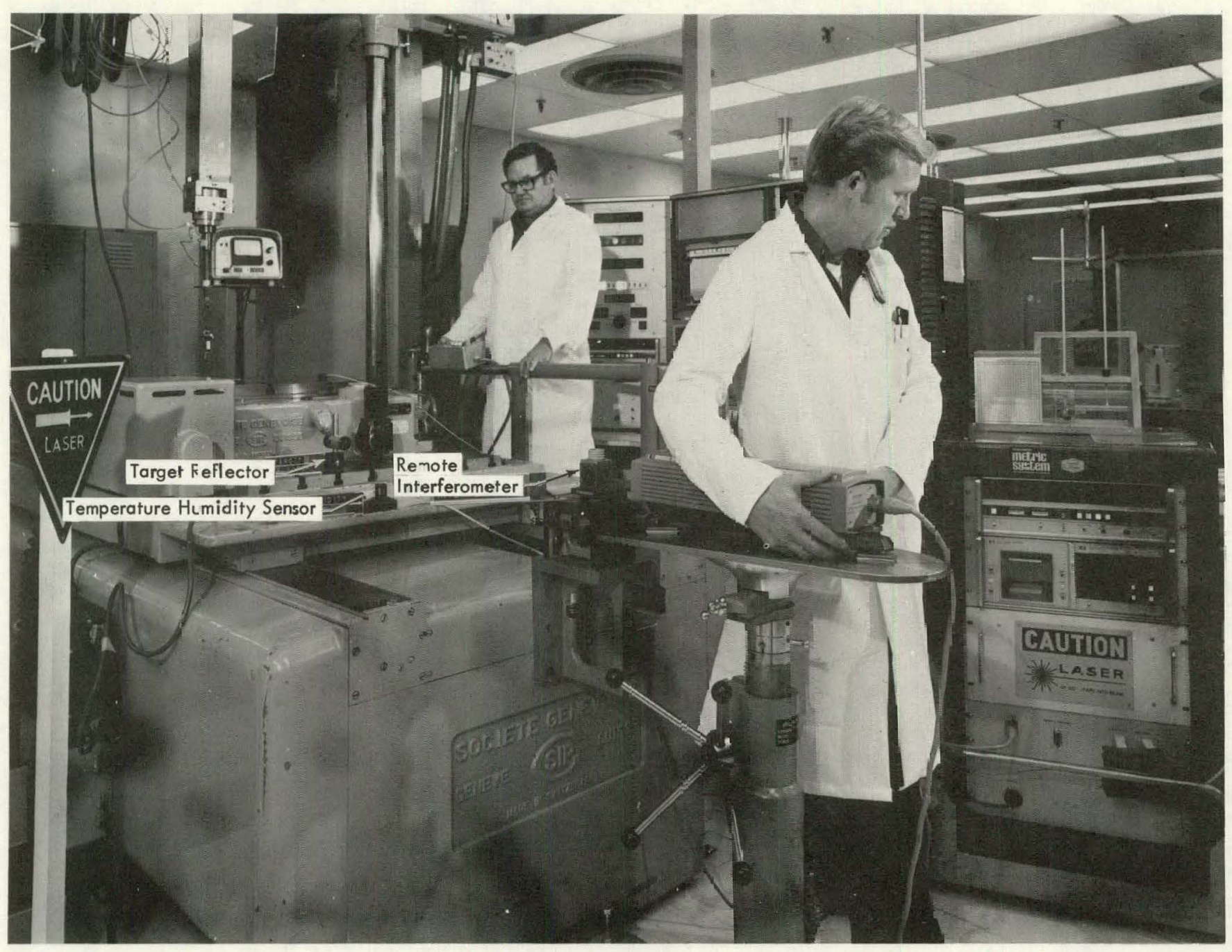

Figure 3. LASER SYSTEM USED TO CA LIBRATE THE SIF 7AM MEASURING SYSTEMS.

168754 

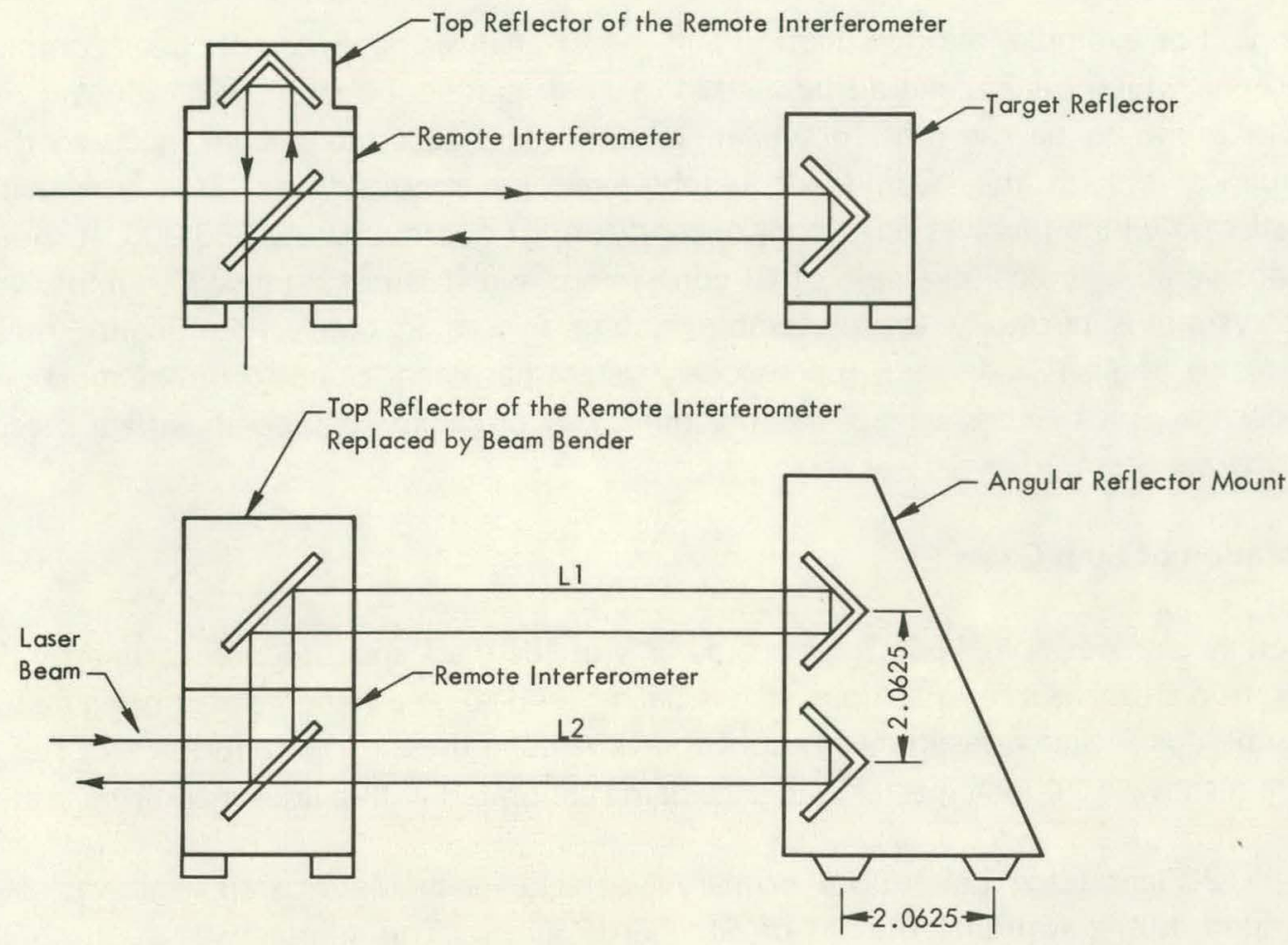

Notes:

1. Foot spacing of the Angular Reflector mount is equal to the spacing of the reflectors $=2.0625$ inches.

2. Displacement of the heel of the Angular Reflector is equal to the difference in the length of the laser beam (LI-L2) when the Angular Reflector is tilted.

3. Set tilt $(L 1-L 2)=0.000010^{\prime \prime}$

$$
\text { Then } \begin{aligned}
\operatorname{Sin} \theta & =\frac{(L 1-L 2)}{2.0625}=\frac{0.000010}{2.0625} \\
\operatorname{Sin} \theta & =0.00000485 \\
\theta & =1 \mathrm{sec}
\end{aligned}
$$

4. If $\mathrm{L} 1-\mathrm{L} 2=0.000001$ ", then $\theta=0.1 \mathrm{sec}$ Laser display indicates seconds of tilt.

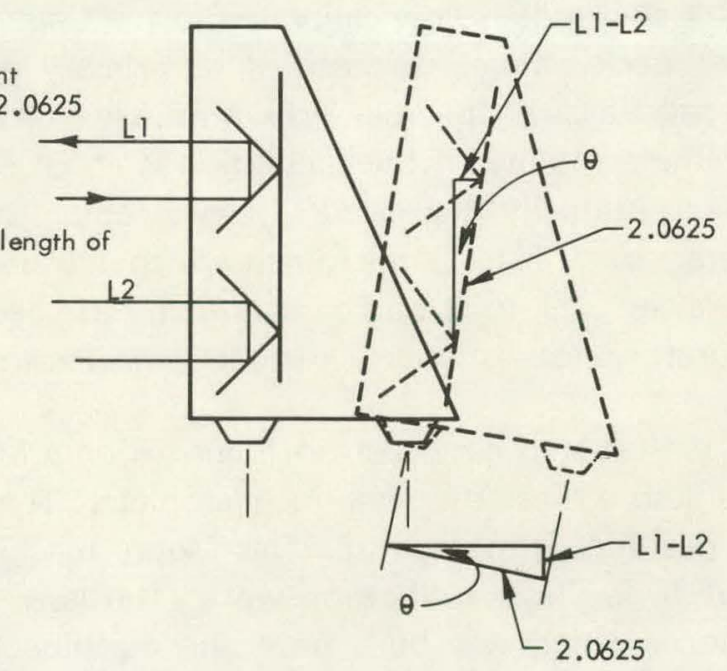

Figure 4. ANGULAR REFLECTOR. (Setup and Operating Principles)

linear distances exceeding 24 inches, where a step master and staging process is normally required.

The SIP 7AM machine (Figure 3) is equipped with an English measuring system. Conversion of the measuring system on this machine to a dual English-SI system is now in process. It has been found that in converting a machine measuring system from English to the dual English-SI system, it is, in some cases (particularly where optical-scale-line standards are involved), more economical to convert to a laser system than any of the other available 
options. For example, an investigation and a cost analysis have recently been completed to determine which system should be used in this particular conversion. Not only was the laser system found to be the most practical, versatile, and accurate system, but also the most economical system that would adequately meet the requirements. This conversion is a special case which involves an overall expenditure of approximately $\$ 50,000$. It should not be considered a typical example of SI conversion, and it is not intended to imply that the laser system is normally the preferable system to use in converting English measuring systems to English-SI. In fact, the encoder system has been found to be the most practical approach in most cases where the machine was originally equipped with a mechanical lead-screw system.

\section{Calibration of Step Gages}

Although the portable laser interferometer was justified and procured primarily for the calibratlon of measurıng machınes, it has been found to be a valuable measuring instrument in numierous other measurement applications. Among these is the calibration of step gages. Figure 5 shows a 24 -inch master step gage being calibrated with a laser measuring system.

The Y-12 Plant Gage Laboratory Primary Master 24-inch Moore step gage was originally calibrated at the National Bureau of Standards (NBS). This master was at the NBS and, consequently, out of service for a period of more than two years during the calibration. This master step gage is now calibrated in the Gage Laboratory using a laser interferometer. The laser interferometer is classified as primary equipment. Therefore, the master step gage calibrated against the laser system must be classified as a secondary standard, but it is felt that the reliability of the calibration is about equal to the original NBS calibration due to the exceptionally high accuracy levels obtainable with the laser meası iring system. Overall accuracies of 1 to 2 microinches/inch are quoted by the equipment manufacturer, and accuracies of 1 to 3 microinches/inch have been obtained in $Y-12$ Gage Laboratory tests. Laboratory tests, of course, include inspector error in addition to equipment error.

The master step gage seen in Figure 5 on a Model $4 Z$ Moore measuring machine is being calibrated against the laser interferometer. The Moore machine is used solely as a holding and positioning mechanism. This Moore machine was designed with sperial features that adapt it for laser calibration work. The laser sensing head is positioned on a stationary platform which was built onto the machine for this purpose. The cube corner (target) reflector is aligned on the machine hed and moves with the bed in a transverse direction. The step gage is aligned on the machine bed parallel to the machine transverse travel and parallel to the laser beam. An electronic gage head on the vertical spindle is zeroed on the datum or zero-inch lug of the step gage. The laser readout is also zeroed at this point. The machine table is then moved to each lug on the step gage and the amount of movement is read from the laser digital readout. Any variation in the laser readout and the unit of movement is the error in the step gage.

As previously mentioned, the former method of certifying a Moore step master was to send it to the NBS for calibration. Individual one-inch intervals of this 24 -inch step master could 


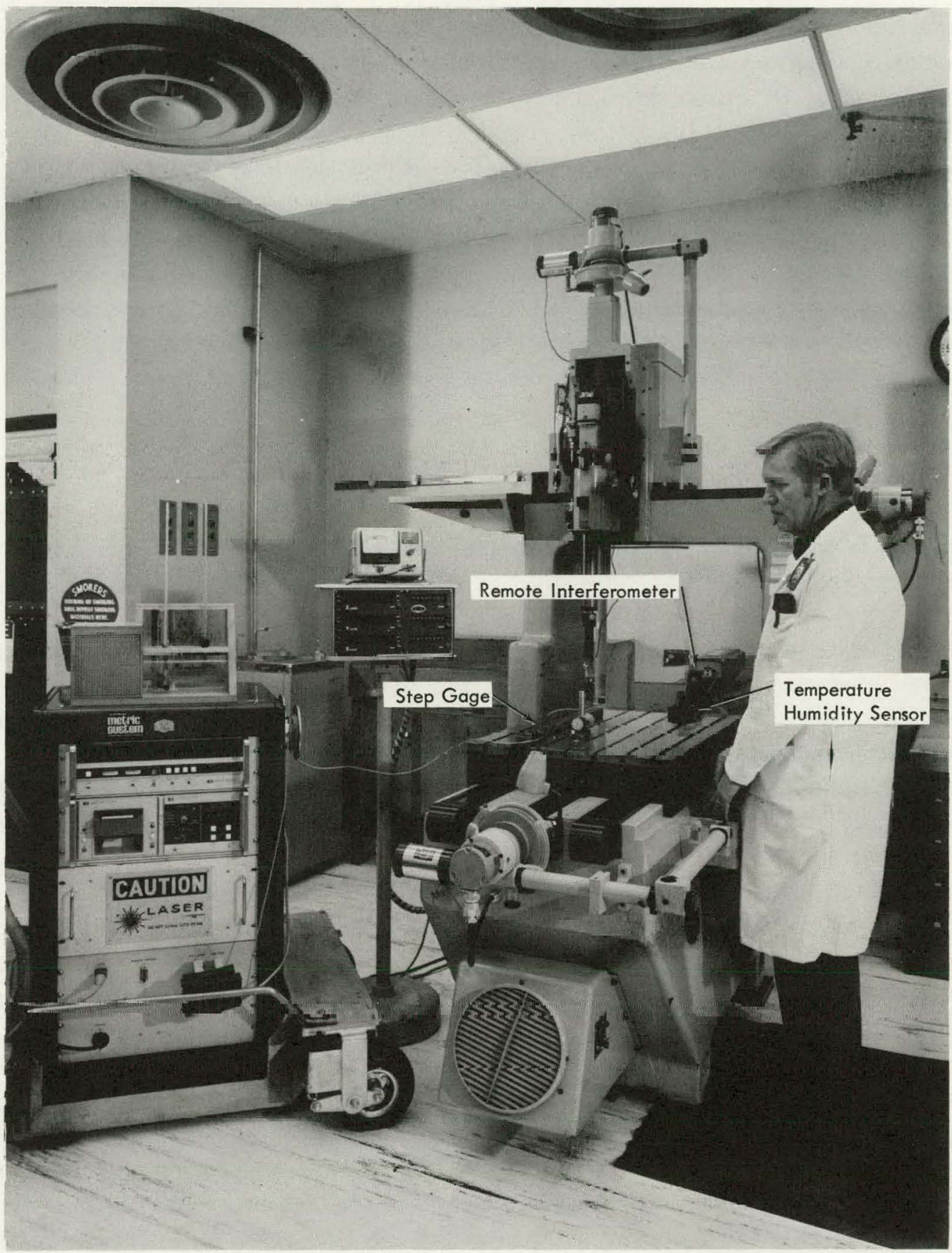

168753

Figure 5. A 24-INCH MASTER STEP GAGE BEING CALIBRATED WITH A LASER MEASURING SYSTEM.

be calibrated in the $\mathrm{Y}-12$ Gage Laboratory using differential gage heads, primary standard gage blocks, and a very tedious process of mathematical computation. These methods are both costly and time consuming. A precision step master (normally accurate within a few ppm) can be calibrated by laser interferometry in the $\mathrm{Y}-12$ Gage Laboratory in an eight-hour shift with accuracies of approximately $3 \mathrm{ppm}$. Special calibrations of precision 
step masters are made on request to much better accuracies ( 4 microinches $+1 \mathrm{ppm}$ ). Such calibrations involve an averaging of several complete calibrations. Accuracies in this range are not normally obtainable from the NBS nor can they be obtained by other calibration methods in the $\mathrm{Y}-12$ Gage Laboratory.

The measuring system on the Moore $4 \mathrm{Z}$ measuring machine (Figure 5 ) is presently in the process of being converted from English to a dual English-SI system. As the encoder system adequately meets the present requirements, is readily adaptable to the Moore measuring machines, and requires an initial capital investment of less than $\$ 8500$, it was selected as the new English-SI measuring system for this machine. A comparable laser system would involve a capital expenditure approximately four times that of the encoder system.

\section{Calibration of Linearity Checkers}

Many groups within the $\mathrm{Y}-12$ Plant use precision micrometer heads mounted on special fixtures to calibrate dial indicators, electrojets, and other linear measuring devices. This category of gages, classified as "linearity checkers", has been found to be very adaptable to calibration by the laser interferometer system. Figure 6 is a view of such a calibration being performed. In this photograph, two inspectors are shown performing the calibration; normally, however, only one inspector is required to certify gages of this type. The inspector, adjusting the micrometer spindle, can easily read the measurement from the digital console and record the reading from his position with no assistance. The equipment in the picture is positioned to give the reader the best view of the complete operation. In actual practice, the inspector would normally stand directly in front of the micrometer head and turn the spindle with his right hand while looking directly into the digital display console. (These facts should be kept in mind while viewing this and the remainder of the photographs in this section, as most of the pictures were made to provide the best overall view of the equipment involved.) In the picture, the precision micrometer head has been removed from the linearity checker and placed in a $V$ block; a special lightweight cube-corner mirror (target reflector) is inserted on the end of the micrometer spindle, and a small cylindrical guide bar is permanently attached to the target reflector. The target reflector moves with the nonrevolving micrometer spindle, while the guide bar rides in a track which is parallel to the spindle motion. This action can be seen more clearly in the small inset picture. The controlled travel of the guide bar minimizes the lateral movement of the spindle which would normally deflect the path of the laser beam, causing an error signal to appear. The laser head is positioned to direst the laser beam in a path contacting the target reflector and returning in a parallel path through the remote interferometer to the fixed interferometer inside the laser head. There, each $1 / 4$ wavelength of laser light corresponding to the movement of the target reflector is sensed, and corresponding pulses are relayed to the computer where the $1 / 4$ wavelengths are automatically converted to inches or millimeters and displayed on the console. There are approximately 100 of these linearity checkers in use throughout the $\mathrm{Y}-12$ Plant, all of which are recalibrated on regular intervals in the Gage Laboratory. The average time required to calibrate a linearity checker, using the laser interferometer, is one hour compared to about four hours using conventional methods. Most important, however, is that there is an improvement in accuracy and repeatibility of approximately 3 to 1 . 


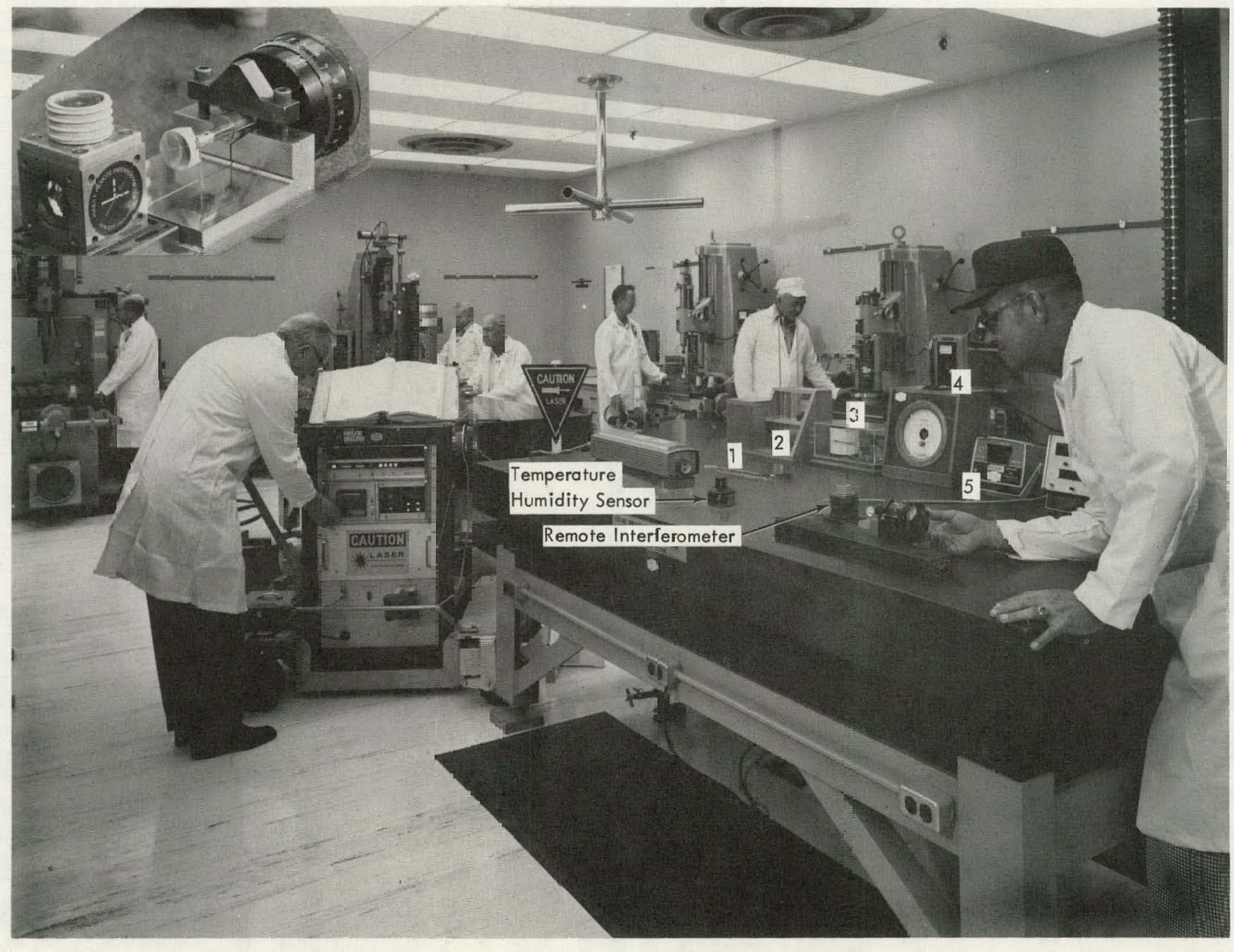

Figure 6. CALIBRATION OF LINEARITY CHECKE=S.

$16 \varepsilon 756$ 
The ambient temperature and humidity sensor can be seen close to the laser beam. This sensor is a part of the automatic environmental correction system which corrects for the deviation in wavelength due to changes in humidity, ambient temperature, and barometric pressure. The barometric pressure sensor is contained inside the display console. Environmental control reference instruments can be seen on the surface plate. These instruments are seen more clearly, and individually identified, in later photographs (Figures 7 and 10). An error light, seen in the upper left corner of the laser console, blinks on and off when a counting error has been made as a result of an interruption in the laser beam, a rapid movement of the target reflector, poor beam alignment, or a maladjustment of the laser tuning circuit.

The actual amount of movement of the micrometer spindle is digitally displayed on the upper dial of the console in microinches. A flip switch will convert from English to SI measurements. A printout tape can be seen on the left front of the display console.

\section{Calibration of Straightness Masters}

Straightness masters are calibrated, as shown in Figure 7. Another set of optical accessories is required in this calibration. This picture shows how the straightness (flatness and/or parallelism) of a four-foot master straightness and parallel bar is calibrated. In this calibration, the top reflector of the remote interferometer is replaced by a special beam bender, seen directly in front of the laser head. This arrangement is seen more clearly in the illustration (Figure 4). The cube-corner (target) reflector is replaced by a special angular reflector mount (also shown in Figure 4). The inspector on the left is positioning the angular reflector mount. Any angular change (pitch) in this unit from its original datum position is indicated on the digital display in microinches or seconds. (One microinch on the display is equivalent to 0.1 second of arc.) Two contacting feet of the sliding angular reflector are separated by a specific distance that allows for a one-microinch difference in the elevation of the supporting feet (front foot with respect to the back foot) to equal exactly 0.1 ser.nnd of angular tilt (Figure 4).

Once the alignment is complete, straightness or flatness calibrations are made in a manner identical to that using the autocollimator method. The laser, however, has two distinct advantages: (1) the conversion from seconds to inches or millimeters is automatic, and (2) the laser is much easier to read than the autocollimator and, therefore, more accurate since there is no optical reading error in the laser digital readout.

The inspector on the right is reading the angular tilt from the digital readout on the laser console. This information can be recorded automatically on the printout seen on the upper left side of the laser console. Yaw can be checked in a similar manner (for linear motion checks) by turning the remote interferometer and the angular reflector to a 90-degree position and realigning the laser beam.

A better view of the environmental reference instruments is provided in this photograph: 1 -sling psychrometer, 2 -hygrometer, 3 -permanent record barometer, 4-precision 


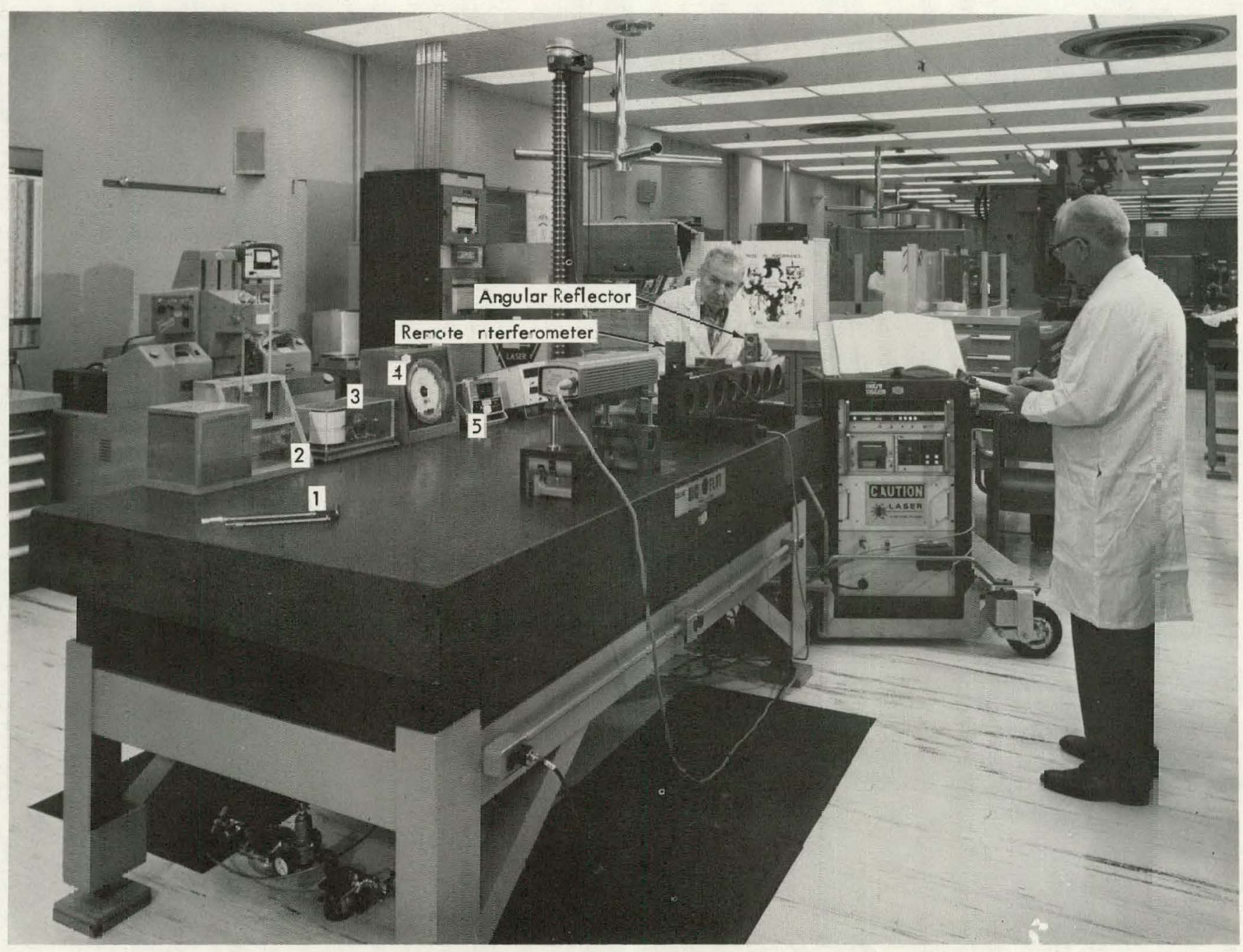

Figure 7. MET IこD FOF CALIBRATING STRAIGHTNESS MASTERS.

168758 
aneroid barometer, 5 - digital temperature display (in units of $0.010 \mathrm{~F}$ ). These instruments are used for checking the accuracy of similar automatic correcting instruments built into the laser system.

\section{Calibration of Large Vernier Calipers}

Precision measurements involving unusually long linear distances are frequently required in the Y-12 Gage Laboratory. A typical example of such a calibration is the eight-foot vernier caliper seen being calibrated in Figure 8. The laser interferometer combined with a microscope has been found to be ideal for this type of measurement.

The eight-foot scale is seen tied firmly to a ten-foot-lonq surface plate. The laser beam emitted from the laser sensing head strikes a 90-degree beam bender, then proceeds to the cube-corner (target) reflector which is attached to a sliding microscope. The laser beam returns in a parallel path to the laser interferometer located inside the laser sensing head Any movement of the microscope along the edge of the scale is displayed on the laser console digital readout. The microscope is first aligned so that the entire eight feet of travel of the microscope along the scale can be made without losing the path alignment of the laser beam. The microscope is then set on the datum or zero mark of the scale. At this point, the laser digital readout is reset to zero. The microscope is moved to random points on the scale, and the actual distance moved is displayed on the digital readout. Results can be recorded manually or by a tape printout.

The remote interferometer would normally be placed between the laser head and beam bender, but is not shown here as it would obstruct the view of the laser head.

The laser interferometer is of particular value in a measurement of this type and range, as there is presently no other method (at the $\mathrm{Y}-12$ Gage Laboratory) of calibrating an eight-foot-long precision scale without staging. A similar calibration, carried out hy using length standards and a process of staging, would not only be cumbersome and impractical, but would require five to six times as long to make a less-accurate calibration. The laser is not only an efficient method for measurements of this type, but is also a very accurate and reliable method. Measurements over several feet can be made with accuracies (ppm) closely comparable to those in the 0 to 12 -inch range.

Measurements of the type seen in Figure 8 can be performed with one inspector, as can most of the laser calibrations illustrated in this report. (The inspector in the background is performing another operation and is not involved in the laser calibration work.)

\section{CERTIFICATION, MAINTENANCE, AND TRANSPORT OF THE PORTABLE LASER SYSTEM}

Like most precision measuring instruments, the laser interferometer should be treated with care and regularly calibrated to assure long and dependable service. 


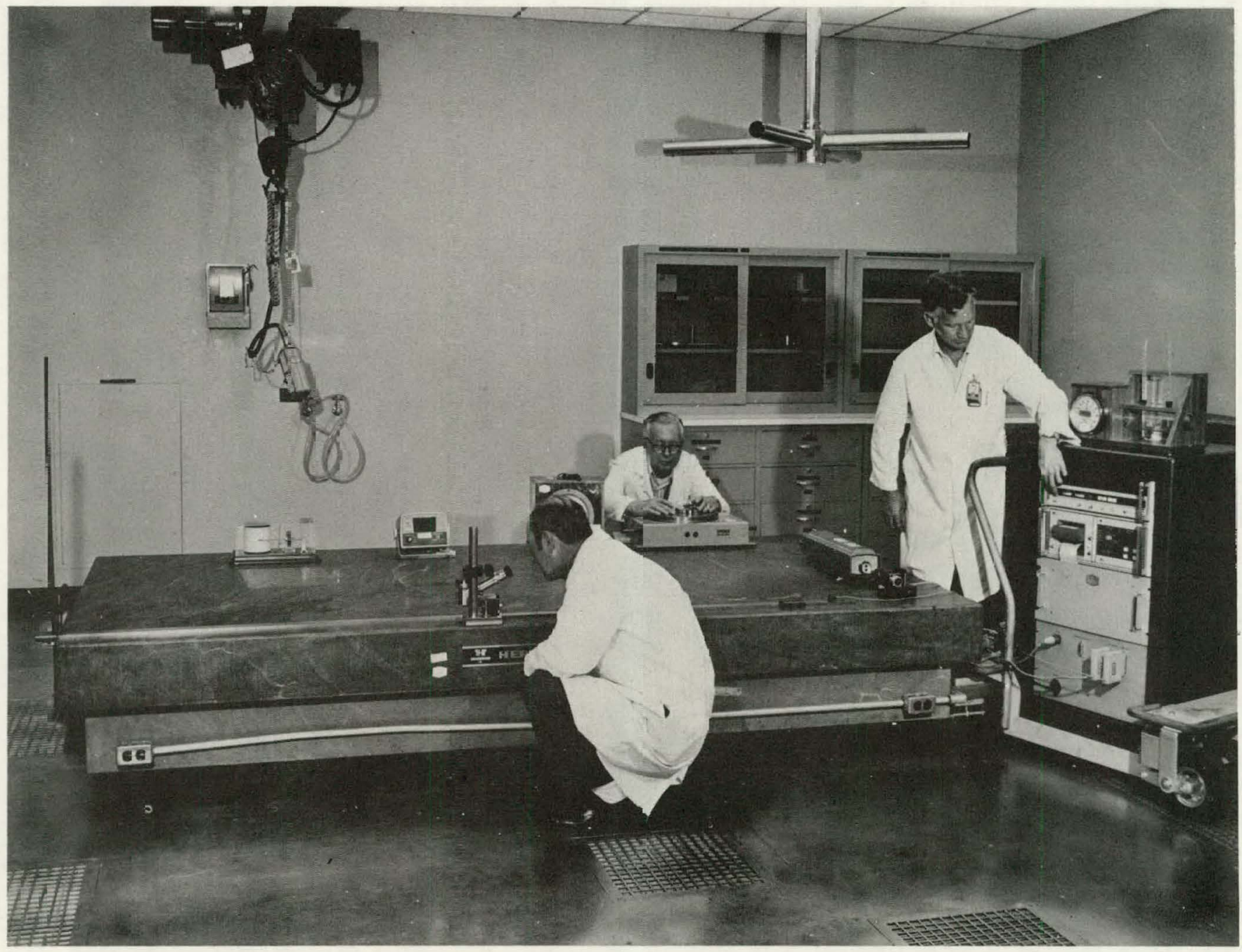

Figure 8. CALIBRATION OF LARGE VERNIER CALIPERS

155178 


\section{Certification of Measurement Accuracy}

The accuracy of the portable laser measuring system is certified in the Gage Laboratory prior to each use. A method of calibrating the measuring accuracy of the laser system has been established which is fast and efficient. The measuring accuracy of the laser system is certified by directly comparing the laser measuring system (readout) to a 4, 10, and 20-inch NBS-certified gage block. In Figure 9, the laser measurement is being compared to the 10 -inch gage block. The quick-check calibration requires less than one hour and immediately indicates any significant measurement error.

The coefficient of linear expansion of the master gage blocks (or any part measured by the laser system) must be dialed into the compensation thumb wheels on the front of the display console. (This is the only correction factor that cannot be entirely compensated for automatically.) Upon completion of each measurement, the gage block length [corrected to $68^{\circ} \mathrm{F}\left(21^{\circ} \mathrm{C}\right)$ ] is displayed on the console in English or SI units. The present procedure requires that the readout agree with the NBS gage-block calibrations within $3 \mathrm{ppm}$ before laser is acceptable for use as a certification system.

\section{Calibration of the Automatic Compensator}

The velocity of light emitted by the laser varies with the ambient temperature, barometric pressure, and relative humidity, causing a direct variation in wavelength. Since the laser system essentially counts waves (fringes corresponding to $1 / 4$ wavelengths) and multiplies by the total number of $1 / 4$ wavelengths prior to a measurement display on the console, it is necessary to correct for changes in environmental conditions. The $\mathrm{Y}-12$ system is equipped with an automatic compensator. This compensator also corrects for changes in part (test piece) temperature from standard conditions. It is necessary, however, to dial in the coefficient of thermal expansion before part expansion or contraction is entered into the automatic compensating system.

In the transposition of fringe counts ( $1 / 4$ wavelengths) to inches or millimeters, fringes are counted and multiplied by a constant for the standard (in vacuum) 1/4 wavelength. The automatic compensator computes and applies a correction factor to the standard $1 / 4$ wavelength at the rate of two times per second, thereby converting standard wavelength to the wavelength at the existing conditions.

Measurement errors due to wavelength changes and expansion or contraction of the test piece are, therefore, accounted for automatically and continually during a calibration. If, for some reason, a failure occurs in the automatic compensating equipment, a correction factor can be dialed into the system. Corrections will then be made automatically, but not continually.

For laser systems not equipped with an automatic compensator, a correction factor must be calculated or taken from a table and dialed into the laser computer system. The manually applied correction will then apply throughout the calibration, or until a new factor is dialed. 


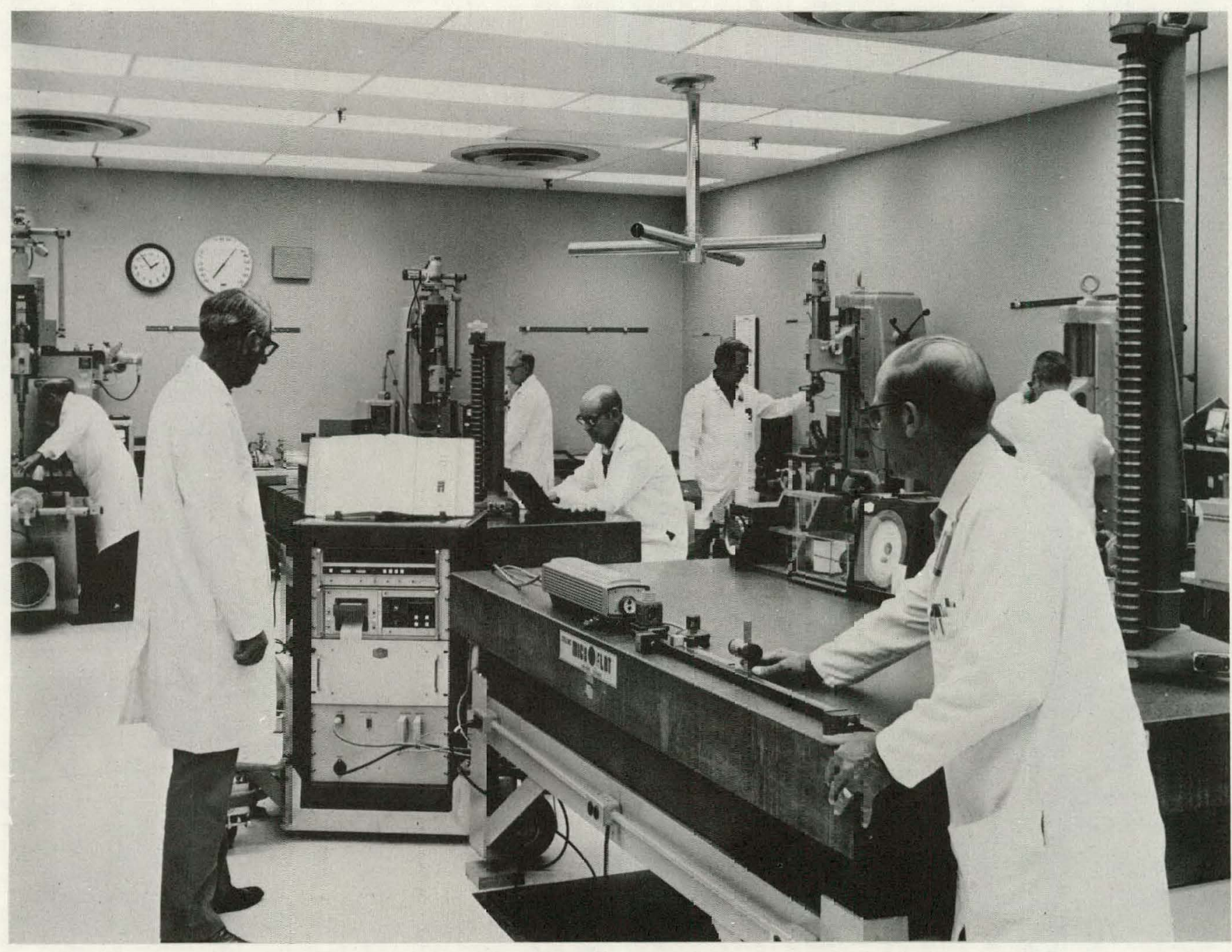

Figure 9. METHOD FOR CERTIFYING MEASUREMENT ACCURACY O= THE LASER SYSTEM.

155177 
Thus, unless environmental conditions are stable, unacceptable errors may be encountered.

The automatic compensator should be checked out on regular intervals. The instruments in the laser system which continually sense barometric pressure, ambient temperature, humidity, and part temperature must be calibrated against acceptable standards. A calibration is being performed in the view of Figure 10. The master instruments are shown on the surface plate: 1 and 2 - a sling psychrometer and hygrometer for checking humidity, 3 and 4 - two barometers for checking barometric pressure, 5 - digital thermometer which checks ambient temperature and part temperature. Individual switches available on the display console permit readings from each of the four environmental sensing instruments contained in the console to be displayed on the digital readout. These instrument readings are compared to the readings from the master instruments on the surface plate.

In operation, each of the environmental factors is independently sensed and a signal is sent to the computer where one correction factor is automatically computed for all of the environmental factors affecting the measurement. Another switch on the laser console displays the computed correction factor. The accuracy of this correction factor is checked by comparing it to a factor manually computed from the environmental conditions shown on the master instruments. The procedure requires that the automatically computed factor agrees with the manually computed factor within $11 / 2$ significant digits (representing a $\pm 11 / 2$ ppm measurement error) before the automatic compensating system is acceptable for use.

Convenient reference tables are available for manually determining the environmental correction factors. An overall correction factor can be extracted and tabulated from these tables in $10-15$ minutes by a trained inspector. These tables can be seen in the photograph (ready for quick reference) on top of the laser display console.

\section{Annual Instrument Certification and Maintenance}

Annual certification of the portable laser system has two purposes: (1) to certify the electrical and instrumentation components of the system, and (2) to provide a preventive maintenance checkup. Measurement accuracy is not involved in this certification.

There are approximately 100 dimensional measuring laser interferometers in the $\mathrm{Y}-12$ Plant. By far the majority of these measuring systems are permanently attached to measuring and fabrication machines. The Maintenance Division has a well-equipped Laser Maintenance Shop that is staffed with competent technicians. The shop provides electrical and instrument certification in addition to preventive and corrective maintenance on any laser system, as required. Annual certification of the Gage Laboratory portable laser interferometer is conducted, as shown in Figure 11.

An annual certification of the Gage Laboratory's portable laser interferometer system includes: (1) calibration of several highly accurate voltage regulators in the computer system and display console, (2) measurement of the power output of the laser system (the laser 


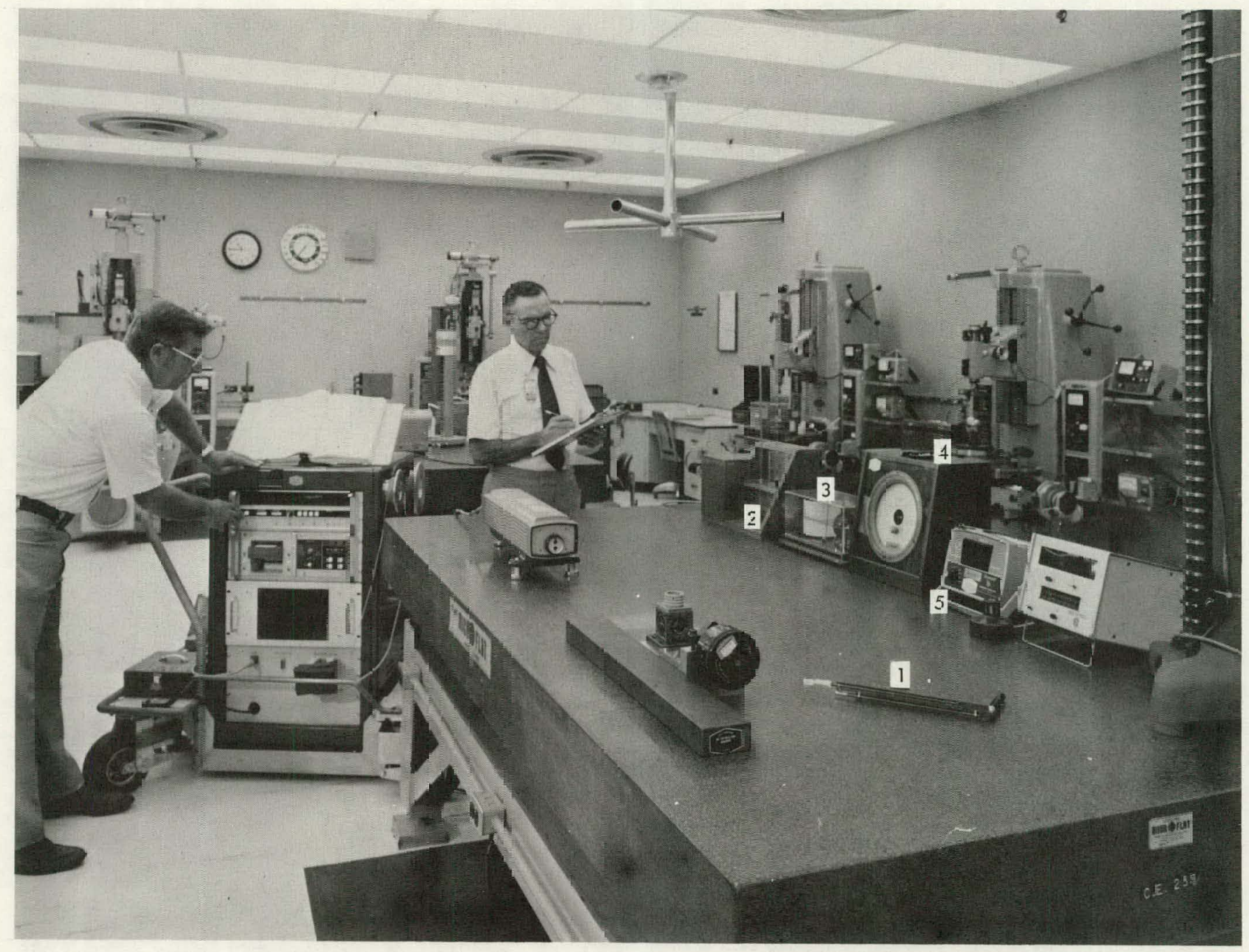

Figure 10. CALIBAATING THE AUTOMATIC COMPENSATOR.

$1 € 8755$ 


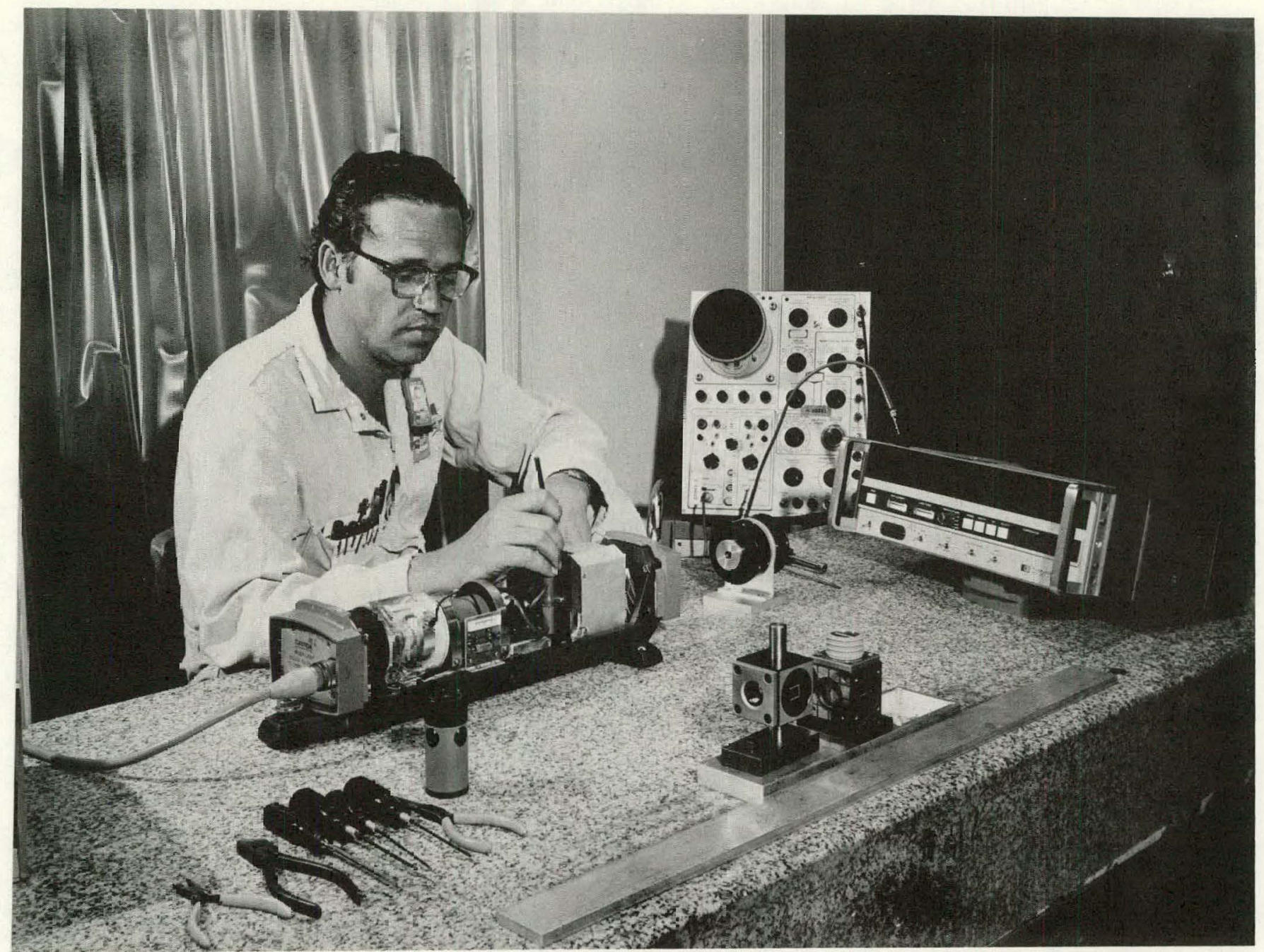

FigLre 11. ANNUAL CERTIFICATION OF THE PORTABLE LASER INTERFEROMETER.

155187 
tube in the $\mathrm{Y}-12$ Gage Laboratory system has a rated power output of 40 - 100 microwatts), (3) calibration of all environmental instrument and part temperature probes, (4) preventive maintenance inspection, (5) certification of the complete electrical and instrument system, and (6) application of a label showing the certification and expiration dates.

\section{Handling and Transport}

As was noted earlier, the laser interferometer is a precision measuring system and should be handled accordingly. Figures 12 and 13 show the laser interferometer (the complete portable laser system with accessories) on its mobile cart being loaded into the Laboratory truck. Gages and machines are regularly calibrated in distant buildings with the $\mathrm{Y}-12$ Plant. The mobile cart was designed to provide safe, convenient, and shock-resistant transportation. The four balloon tires are spring loaded and have ball-bearing swivel casters. Bump bars are covered in a special shock-resistant rubber material. A pull-out, retractable-type extension cord is included on the rear panel. The hydraulic gate lift onto which the laser is being loaded was specially designed for transporting the laser unit. Special tie-down straps, bolted to the truck frame, hold the dolly and laser firmly in place while in transit. Many other safety features were incorporated. After five years of transporting the laser system, no noticeable damage has occurred.

\section{CONCLUSIONS}

Several practical applications of the portable laser interferometer have been described and illustrated. While it is not the primary intent of this report to recommend the laser system as a superior method of dimensional measurement, it is firmly believed that many laboratories not presently using the laser system as a measuring tool may benefit from its use. The attainment of these benefits, however, is dependent on several major factors: (1) the availability of qualified technical, maintenance, and operating personnel; (2) the facilities to maintain and service precision environmental control equipment, and (3) a sufficient volume of measırements requiring the precision and accuracy provided to justify system costs.

While there are many advantages in using laser measuring systems, there are also some disadvantages. The greatest disadvantage, with the exception of the requirements for specialized personnel and environmental equipment previously mentioned, is the initial cost of a laser measuring system. An investment of 20 to 25 thousand dollars is required for the very basic components of a laser measuring system, while a more elaborate system may cost as much as 50 thousand dollars.

Even though laser measuring systems are quite expensive, their use can, in many cases, be justified by one or more of the following attributes:

1. The system is versatile. There is probably no one measuring system that can perform such a variety of measurement functions while being so readily portable and adaptable to unique setup arrangements. 


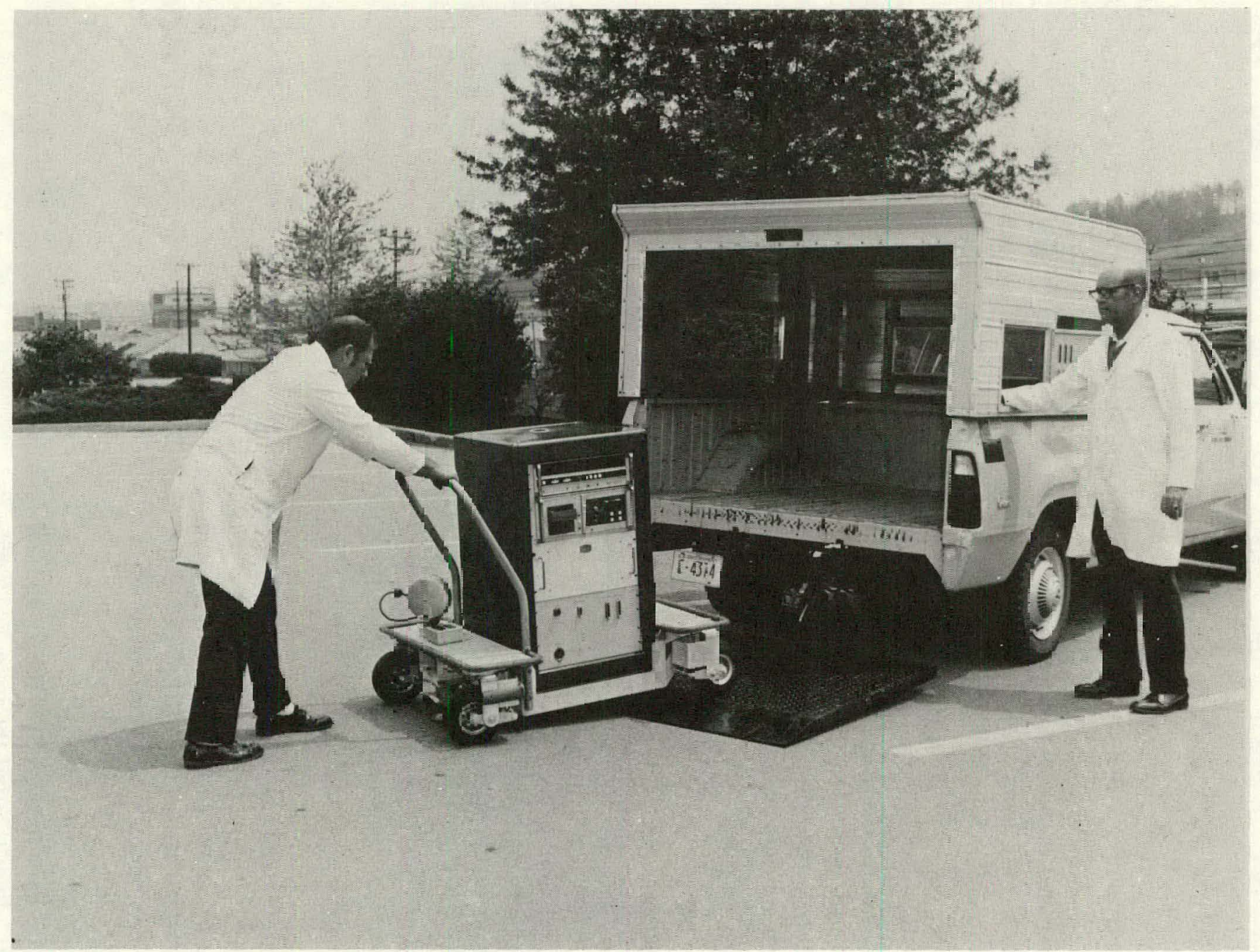

Figu : 12. MOBiLE CART FOR TRANSPORTING THE LASER IVTERFEROVETER.

155184 


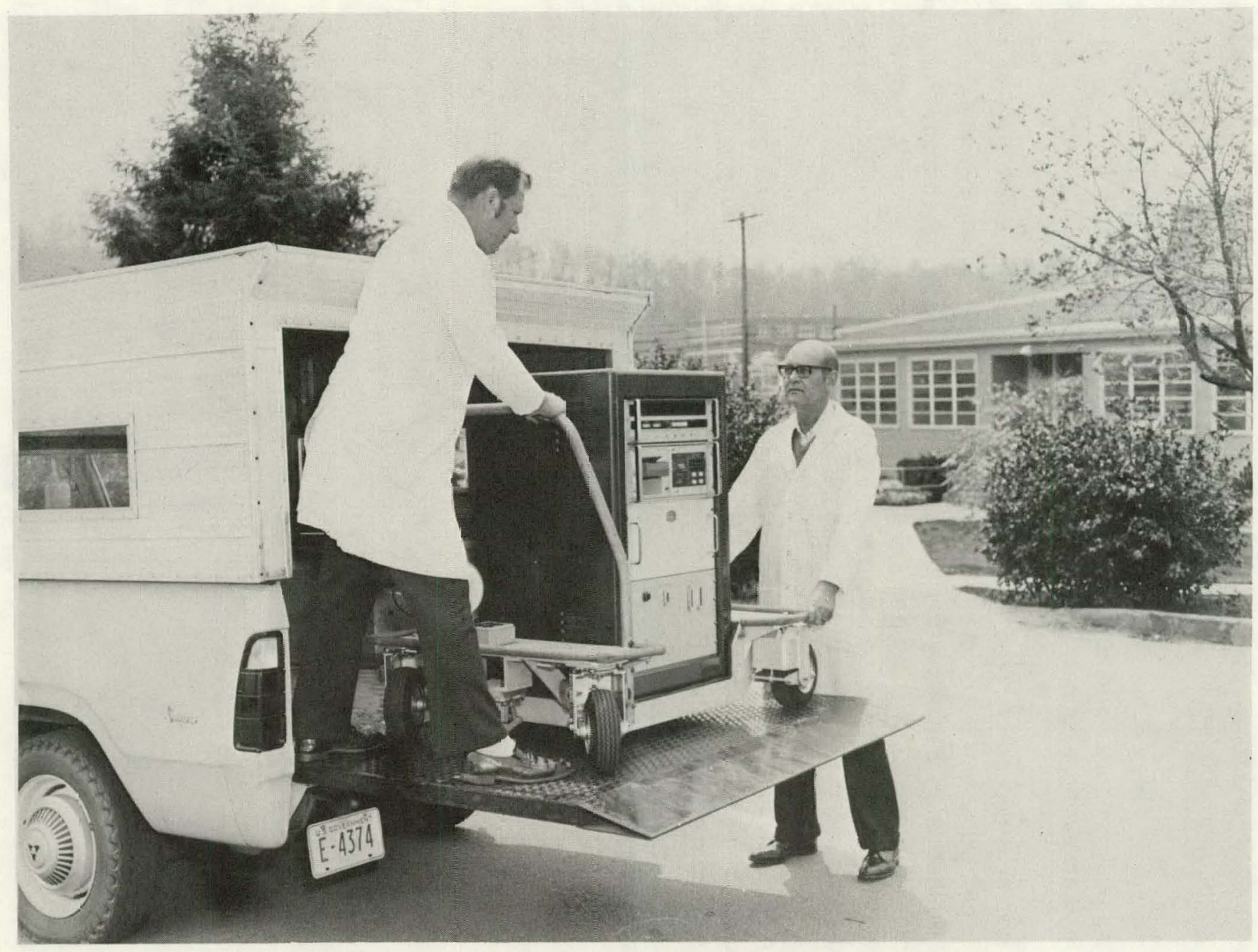

Figure 13. DEVICE FOF: LIFTING THE LASER CART INTO THE TRUCK.

155176 
2. The system is accurate. It has been possible to improve accuracies, in some cases, by factors of 2 to 4 over conventional methods. Linear measurements over several feet can be made with accuracies closely comparable to those in the range of a few inches. Although the laser system has never been used in the Y-12 Gage Laboratory for measurements exceeding 12 feet, the manufacturer specifies accurate measuring capabilities up to 200 feet ( 1 - 2 ppm).

3. The system is fast. Calibration time has been reduced by 30 to $75 \%$ compared to conventional methods. Greatest improvements have been realized in the calibration of multiaxis measuring machines.

4. The system is dependable. The service record of the Gage Laboratory's portable laser interterometer system is commendable. It has been in use for appruximalely six years with a minimum of downtime. For an instrument that is filled with so many critical and delicate instruments, it is amazingly stable. Laser measuring systems permanently attached to measuring machines are, due to their permanence and immobility, even more maintenance free than the portable laser system.

5. The system has future potential. Advancements in laser technology are rapidly adding to its scope of measurement application. Recent models have already been modified to allow several measurements to be made simultaneously from a single laser source.

6. The system is safe. Although caution signs are used in areas where the laser is located, the light beam from the laser interferometer is generally considered to present no hazard to health or safety when the laser and interferometer are combined as a unit. It is, however, recommended that only a laser specialist separate the laser from the interferometer for maintenance and/or power peaking.

7. The system is, in particular cases, a worthy prospect when considering the conversion of an English measuring system to a dual English-SI system; and, in some cases, is the most practical conversion method. 


\section{Distribution}

Aerojet Nuclear Corporation

Sexey, M. J.

Bendix Corporation

Hadley, J. F.

EG\& G, Incorporated

Barger, $\mathrm{R}$,

Energy Research and Development

Administration - Oak Ridge

Hickman, H. D.

Leed, R. E.

Zachry, D. S., Jr

General Electric -

St. Petersburg

Stanisavljevich, N. D.

Lawrence Livermore Laboratory

Nelms, W. S.

Los Alamos Scientific Laboratory

Colston, E. W.

Mason Hanger - Silas Mason - Amarillo

Wilcox, R. A.

Mound Laboratory

Bent, H. E.

Oak Ridge Gaseous Diffusion Plant

Stief, S. S.

Wilcox, W. J., Jr

Oak Y-12 Plant

Abbatiello, L. A.

Alvey, H. E.

Arehart, T. A., Jr

Arnold, J. B.

Baldauf, W. A.

Bernander, N. K.

Black, B. E.

Bright, G. R.

Briscoe, O.W.

Burditt, R. B.

Burrus, B. M. (50) 
Campbell, C. W.

Denny, E. C.

Douglass, S. S.

Duggan, H. G.

Foulk, D. L.

Fraser, R. J.

Goodwin, W. L.

Green, R. C.

Groppe, W. A.

Hall, W. H.

Hayes, C. C.

Jackson, V. C.

Jones, F. W.

Kahl, K. G.

Keith, A.

Kite, H. T.

Lay, C. M.

Marcum, R. C.

Martin, W. R./Googin, J. M.

Mason, D. L.

McLendon, J. D.

Mills, J. M., Jr

Noey, J. L.

Oliphant, G. W.

Phillips, L. R.

Robinson, T. W.

Rose, R. P.

Schede, R. W.

Smith, J. H.

Smith, R. D.

Stoner, H. H.

Steger, $\Gamma$. J.

Swarts, H. S.

Tewes, W. E.

I hompson, C. H.

Tunnell, H. A:

Weathersby, W. E.

Whitson, W. K.

Whitton, L. G.

Wright, C. C.

Yaggi, W. J.

$Y-12$ Central Files (master copy)

$Y=12$ Eerilial Files (ruulu cupy)

$Y$-12 Central Files ( $Y$-12RC)

$Y-12$ Central Files (5)

\section{Paducah Gaseous Diffusion Plant}

Bewley, H. D.

Rockwell International - Rocky Flats

Hilbig, R. A.

Sandia - Albuquerque

Meikle, J. R.

Sandia - Livermore

Wilson, J. L.

\section{Savannah River Plant}

Hardison, H. V.

Westinghouse - Hanford

Chubb. K. L.

In addition, this report is distributed in accordance with the category UC-38, Engineering and Equipment, as given in the USERDA Standard Distribution Lists for Unclassified Scientific and Technical Reports, TID-4500. 